Federal Reserve Bank of Dallas

Globalization and Monetary Policy Institute

Working Paper No. 305

https://www.dallasfed.org/ /media/documents/institute/wpapers/2017/0305.pdf

\title{
The Exchange Rate Effects of Macro News after the Global Financial Crisis*
}

\author{
Yin-Wong Cheung \\ City University of Hong Kong \\ Rasmus Fatum \\ University of Alberta \\ Yohei Yamamoto \\ Hitotsubashi University
}

February 2017

\begin{abstract}
We explore whether the exchange rate effects of macro news are time- and state-dependent by analyzing and comparing the relative influence of US and Japanese macro news on the JPY/USD rate before, during, and after the Global Financial Crisis. A comprehensive set totaling 40 time-stamped US and Japanese news variables and preceding survey expectations along with 5-minute indicative JPY/USD quotes spanning the 1 January 1999 to 31 August 2016 period facilitate our analysis. Our results suggest that while US macro news are now more important than before the Crisis, the influence of Japanese macro news has waned to the point of near-irrelevance. These findings are of particular importance to exchange rate modeling of the New Era.
\end{abstract}

JEL codes: F31, G15

\footnotetext{
* Yin-Wong Cheung, Department of Economics and Finance, City University of Hong Kong, Tat Chee Ave, Kowloon, Hong Kong. yicheung@city.edu.hk. Rasmus Fatum, School of Business, University of Alberta, Edmonton, Alberta, Canada, T6G 2R6. rasmus.fatum@ualberta.ca. Yohei Yamamoto, Department of Economics, Hitotsubashi University, 2-1 Naka, Kunitachi, Tokyo 186-8601, Japan. yohei.yamamoto@econ.hit-u.ac.jp. Fatum is also Research Associate at the Federal Reserve Bank of Dallas and member of the Economic Policy Research Unit (EPRU) at the University of Copenhagen. Yamamoto is a Fellow of the Tokyo Center for Economic Research (TCER). Cheung gratefully acknowledges the Hung Hing Ying and Leung Hau Ling Charitable Foundation for their support through the Hung Hing Ying Chair Professorship of International Economics. Fatum gratefully acknowledges financial support from a Foote Professorship in International Business. We thank Roger Lee for collecting data on news announcements. The views in this paper are those of the authors and do not necessarily reflect the views of the Federal Reserve Bank of Dallas or the Federal Reserve System.
} 


\section{Introduction}

A considerable literature on the influence of macro news on foreign exchange markets, including several studies investigating the intraday exchange rate effects of such news, exists. ${ }^{1}$ While this body of literature encompasses studies using different methodological approaches and different data sampling frequencies for considering the influence of different types of macro news from different countries on different currencies, the following stylized facts have been uncovered. The exchange rate effects of macro news are substantial (Evans and Lyons, 2008), immediate (Andersen et al., 2003), and shortlived (Andersen et al., 2003); macro news emanating from the US typically matter more than non-US macro news (Chatrath et al., 2014; Evans and Speight, 2010); the influence of macro news tends to be time-dependent and vary across the state of the economy (Clarida and Waldman, 2007; Fatum et al., 2012; Faust et al., 2005). ${ }^{2}$

We take our cue from these stylized facts, particularly as they pertain to time- and state-dependence, to investigate whether the influence of macro news on the exchange rate has changed with the emergence of the Global Financial Crisis (GFC) and subsequent post-GFC periods of increased uncertainty, slow or negative growth, and ultra-accommodative monetary policy stance. In this New Era of economic circumstances where any off-setting policy response to macro news is constrained or unlikely (and thus market expectations in regards to such policy responses are muted accordingly), the

\footnotetext{
${ }^{1} \mathrm{Li}$ et al. (2015) provide a recent survey of the intraday literature on macro news and exchange rates.

${ }^{2}$ Evans and Lyons (2008) suggest that macro news explain more than $30 \%$ of daily exchange rate variance. Andersen et al. (2003) show that the exchange rate adjusts to news quickly in the form of a jump rather than gradually. Chatrath et al. (2014) in their jump diffusion analysis and Evan and Speight (2010) in their study of EUR/USD rate volatility both find that US news matter more than non-US news. Clarida and Waldman (2007) consider the relevance of the state of the economy and associated policy response to news, Fatum et al. (2012) find evidence that the influence of news vary with the state of the economy, and Faust et al. (2005) takes into account the relevance of time-dependence of the influence of macro news.
} 
influence of macro news on exchange rates is possibly magnified. ${ }^{3}$ To investigate whether this is indeed the case and, more broadly, to document and compare the exchange rate effects of macro news before, during, and after the GFC, we analyze the intraday effects on the JPY/USD rate (using 5-minute indicative quotes) of 40 different types of US and Japanese macro news surprises (23 different types of US macro surprises and 17 different types of Japanese macro surprises) over the 1 January 1999 to 31 July 2007 (pre-GFC), the 1 August 2007 to 31 January 2009 (GFC), and the 1 February 2009 to 31 August 2016 (post-GFC) periods. ${ }^{4}$

We focus our analysis on the effects of US and Japanese news on the JPY/USD rate since doing so allows us to take advantage of a unique combination of a largely unchanged Japanese zero-interest rate environment that spans more than 16 years juxtaposed against dramatic shifts in the US (and global) economic environment before, during, and after the GFC. Furthermore, by focusing on US and Japanese news we are able to extend our analysis to separately consider the influence of news during the 9 years of zero US interest rates ("US-ZIRP") in a setting where the state of the economy and the economic policy environment of Japan are mostly constant. ${ }^{5}$ Towards the end of the USZIRP the Japanese monetary policy stance has become further accommodating with the introduction of the Japanese quantitative and qualitative easing (QQE). We also consider separately the influence of news during the Japanese QQE period. ${ }^{6}$

\footnotetext{
${ }^{3}$ An off-setting policy response to negative macro news is necessarily constrained when traditional policy options are exhausted. At the same time, an off-setting policy response to positive macro news is unlikely in a subdued economic environment.

${ }^{4}$ The GFC demarcation dates follow Melvin and Taylor (2009).

${ }^{5}$ The US-ZIRP starts 16 December 2008 and ends 15 December 2015.

${ }^{6}$ The Japanese QQE has been in effect since 5 April 2013. On 29 January 2016 the QQE was expanded to include negative interest rates. The resulting sub-period characterized by negative Japanese interest rates is too short to facilitate a meaningful separate investigation of the influence of news when interest rates are negative.
} 
Using both time-series and event study regressions to model the JPY/USD exchange rate response to US and Japanese macro news our results yield the following new insights. The composition of the set of US macro news that elicit a JPY/USD rate response, i.e. the number of US news as well as the particular types of US news associated with significant exchange rate movements, is very stable across the more than 16 years of data under study. However, we find that the average estimated effect of the significant US news variables has roughly doubled since the inception of the GFC. This is an interesting finding that lends support to the suggestion that, as far as US news goes, the influence of macro news on exchange rates in the New Era of constrained policy options has in fact increased. In other words, our results suggest that US macro news are now more important than before the GFC.

The results pertaining to the effects of Japanese macro news before, during, and after the GFC are very different from those of the US news. For the pre-GFC period we find the set of influential Japanese news to be smaller than that of the set of influential US news, and in terms of average estimated effect relatively less important than US news. To find that the importance of US news dominates that of non-US news is hardly surprising and consistent with the aforementioned studies that consider and compare the relative influence of US news to non-US news. However, we find for the GFC as well as for the post-GFC periods that the influence of Japanese macro news has all but disappeared. This is a particularly interesting finding that might suggest that after two decades of false starts but no real recovery, foreign exchange markets may no longer consider Japanese macro news as important or as reliable indicators of the state of the Japanese economy and, as a result, markets may thus largely ignore news originating 
from Japan at a time when the global economy is experiencing a sustained period of mooted growth that makes positive changes to the Japanese status quo even more difficult to achieve. An alternative explanation is that this finding is not Japan-specific but non-US news in general lost importance since the inception of the GFC (in unison with US news gaining in importance).

In any event, our results constitute important findings of particular relevance to exchange rate of the New Era and, at the same time, our results invite further research to ascertain if US news since the GFC have become universally more important alongside a waning influence of non-US news, or, if our results might be largely US-Japan specific.

The rest of the paper is organized as follows. Section 2 describes the data. Sections 3 and 4 present the econometric methodology and the results, respectively. Section 5 discusses extensions and robustness checks. Section 6 concludes.

\section{Data}

Our analysis employs high-frequency JPY/USD exchange rate data, time-stamped US and Japanese macro news announcements, and survey measures of market expectations of these news announcements. Our full sample covers the 1 January 1999 to 31 August 2016 period.

The JPY/USD exchange rate data is provided by Olsen and Associates. The data consists of the bid and the offer spot exchange rate at the end of every 5-minute interval over every 24 -hour period. The quotes are indicative quotes, i.e. not necessarily traded quotes. ${ }^{7}$ We filter the exchange rate data for outliers using the two-step procedure of

\footnotetext{
${ }^{7}$ The statistical properties of exchange rate return series derived from indicative quotes at the 5-minute sampling frequency are very similar to those of traded ("firm") quotes (see Danielsson and Payne, 2002).
} 
Dacorogna et al. (1993). Our analysis makes use of continuously compounded returns that are constructed as the change in the five-minute average log bid and ask prices. Table 1 summarizes key statistical properties of our filtered exchange rate returns data.

Our news data consists of a comprehensive set of time-stamped Japanese and US macroeconomic announcements and preceding survey expectations obtained from Bloomberg News Service. ${ }^{8}$ Specifically, we consider US news variables that Andersen et al. (2003) find to be significant in their investigation of the JPY/USD exchange rate along with comparable Japanese and other US and Japanese news variables of particular interest included in Fatum et al. (2012). ${ }^{9}$ Our resulting news data includes announcements and survey expectations regarding 23 types of US macro news and 17 types of Japanese macro news. The US news variables are GDP advanced estimate, GDP second estimate, GDP third estimate, Non-farm payrolls, Retail sales, Industrial production, Capacity Utilization, Personal income, Consumer credit, Consumer spending, Personal spending, New home sales, Durable goods orders, Factory orders, Business inventories, Trade balance, Producer price index, Consumer price index, Consumer confidence index, NAPM index, Housing starts, Index of leading indicators and Target Federal Funds rate. The Japanese news variables are GDP preliminary, GDP final, Industrial production, Capacity utilization, Department and super sales value, Overall spending, Machinery orders, Construction orders, Trade balance, Current account, Retail trade, Consumer price

\footnotetext{
${ }^{8}$ Fatum and Scholnick (2008) show that failure to disentangle the expected component of news may lead to an underestimation of the impact of news.

${ }^{9}$ While we investigate the influence of macro news on the JPY/USD rate separately over the US ZIRP and separately over the Japanese QQE period, we do not include in our set of news variables the various US and Japanese announcements associated with quantitative easing innovations as preceding survey expectations pertaining to these typically unscheduled announcements are unavailable. For a study that considers the exchange rate effects of the quantitative easing related announcements see, for example, Arai (2016).
} 
index, Producer price index, Leading economic index, Consumer confidence index, TANKAN large manufacturing index, and TANKAN non-manufacturing index. ${ }^{10}$

Table 2 displays the details pertaining to the US and the Japanese news variables. The table shows the number of non-zero news surprises, the announcement frequency, and the start date of each of the news series. ${ }^{11}$

We follow Andersen et al. (2003) and others in defining a news announcement surprise as the difference between the macroeconomic announcement and the preceding survey expectation of that announcement as well as in standardizing each news surprise series in order to allow for a comparison of the relative influences of the different types of news. ${ }^{12}$

\section{Econometric Methodology}

To assess the influence of US and Japanese macro news surprises on the intraday JPY/USD rate we first estimate the following model:

$R_{t}=\beta_{0}+\sum_{j=1}^{J} \beta_{j} R_{t-j}+\sum_{q=1}^{Q} \sum_{k=0}^{K} \gamma_{q, k} S_{q, t-k}+\varepsilon_{t}$,

10 The Board of Governors of the Federal Reserve System website at https://www.federalreserve.gov/econresdata/releaseschedule.htm provides details regarding the US macro announcements. The Bank of Japan website at www.boj.or.jp/en/theme/stat/index.htm and the Japanese Cabinet Office website at www.cao.go.jp/index-e.html provide details (in English) regarding the Japanese macro announcements.

${ }^{11}$ Andersen et al. (2003) and Hashimoto and Ito (2010) provide additional details regarding US and Japanese news announcements, respectively.

${ }^{12}$ A standardized news surprise is given by the unexpected component of the macroeconomic announcement divided by the associated sample standard deviation. Let $A_{q, t}$ denote the value of a given macroeconomic fundamental q, announced at time (minute) t. Let $E_{q, t}$ refer to the median value of the preceding market expectations for the given fundamental at announcement time $\mathrm{t}$, and let $\hat{\sigma}_{q}$ denote the sample standard deviation of all the surprise components associated with fundamental q. The standardized surprise of macroeconomic fundamental q announced at time $\mathrm{t}$ is then defined as $S_{q, t}=\left(A_{q, t}-E_{q, t}\right) / \hat{\sigma}_{q}$ 
where $R_{t}$ is the five-minute exchange rate return, $S_{q, t-k}$ is the standardized shock of the qth macro news, and $\varepsilon_{t}$ is the error term. The maximum number of US and Japanese macro news included in the model, $\mathrm{Q}=40$, occurs when all news considered in a given sample have non-zero values. The model is estimated using OLS with heteroscedasticity and autocorrelation consistent (HAC) standard errors as suggested by Newey and West (1987). The lag order of exchange rate returns, J, is chosen according to the Schwarz Information Criterion (SIC).

In our main analysis we focus on the contemporaneous effects of news and estimate Equation (1) with $\mathrm{K}=0$ while we in the robustness section consider lagged effects of news by estimating Equation (1) with $\mathrm{K}=1$ and with $\mathrm{K}=2$, respectively. Furthermore, in our main analysis we simultaneously include both US and Japanese macro news when estimating Equation (1) while we in our robustness section estimate separate models for US and Japanese news, respectively.

To analyze whether the absolute effect on the exchange rate of positive news is different from the absolute effect of negative news, i.e. to consider whether the influence on the exchange rate of "good" versus "bad" news is asymmetric, we estimate the following model:

$R_{t}=\beta_{0}+\sum_{j=1}^{J} \beta_{j} R_{t-j}+\sum_{q=1}^{Q} \sum_{k=0}^{K} \gamma_{q, k}^{+} S_{q, t-k}^{+}+\sum_{q=1}^{Q} \sum_{k=0}^{K} \gamma_{q, k}^{-} S_{q, t-k}^{-}+\varepsilon_{t}$

where

$$
\begin{aligned}
& S_{q, t-k}^{+}=I\left(S_{q, t-k} \geq 0\right) S_{q, t-k} \\
& S_{q, t-k}^{-}=I\left(S_{q, t-k}<0\right) S_{q, t-k}
\end{aligned}
$$


with $I(\cdot)$ defined as an indicator function capturing the sign of news surprises. We formally consider whether the coefficient estimates associated with good versus bad news for a given type of news are significantly different by introducing an auxiliary regression where we in Equation (2) replace $S_{q, t-k}^{-}$with $S_{q, t-k}$. Doing so allows the coefficient estimate of $\gamma_{q, k}^{+}$to be interpreted as the difference between $\gamma_{q, k}^{+}$and $\gamma_{q, k}^{-}$in the original Equation (2).

We check the robustness of our main findings by employing two different estimation procedures. First, following Andersen et al. (2007) and others, we assess the influence of news on exchange rates by re-estimating Equation (1) on a reduced sample consisting of only 100-minute windows surrounding every macro announcement considered, where every 100-minute window encompasses observations 10 minutes before and 90 minutes after an announcement. This alteration significantly reduces the number of observations in our sample while keeping information pertaining to the news announcements themselves unchanged.

Second, following Andersen et al. (2003), we also estimate the effects of news using a standard event study regression model:

$R_{t}=\alpha_{q}+\beta_{q} S_{q t}+\varepsilon_{t}$

where this "news-by-news" estimation procedure considers only observations coinciding with an announcement. Equation (3) is also estimated using OLS with HAC standard errors. 


\section{4. $\quad$ Results}

The results of estimating Equation (1) with both US and Japanese standardized news included (contemporaneous news only) across the full sample, 1 January 1999 to 31 August 2016, as well as across the various sub-samples are displayed in Table $3 .{ }^{13}$ The full sample results reported in the first column suggest that 15 of the 23 US news considered are significant at conventional levels (95\% or higher) while only three of the 17 Japanese news considered are significant at conventional levels. All 18 significant coefficient estimates are of the expected sign. The average magnitude of the 15 significant US news variables is 0.0444 and the average magnitude of the 3 significant Japanese news variables is 0.0116 . Overall, these full-sample findings clearly point to a much stronger influence of US news compared to news emanating from Japan.

The magnitudes of the individual coefficient estimates indicate that for the US the forward-looking news variables (in order of relative importance) non-farm payrolls, GDP advanced estimate, and NAPM index are the three most influential. That forward-looking US news variables are of particular importance is consistent with, for example, Chaboud et al. (2004) and Fatum et al. (2012). Consistent with Fatum et al. (2012) and Hashimoto and Ito (2010) we find industrial production to be a particularly influential Japanese news variable.

The second column displays the results pertaining to the pre-GFC period, 1 January 1999 to 31 July 2007. As the column shows, the US news results are mostly very similar to those of the full sample with the most noticeable exceptions being that GDP third estimate is no longer significant while news pertaining to the Target Federal Funds

\footnotetext{
${ }^{13}$ We include three lags of the JPY/USD rate as per the SIC. For brevity we do not display the coefficient estimates associated with constant and JPY/USD lags.
} 
rate is now highly significant. ${ }^{14}$ Overall, similar to the full sample, 15 of the 23 US news considered are significant and of the expected sign and, once again, the average magnitude of the significant US news variables is several times that of the significant Japanese news variables (0.0360 versus 0.0060$)$. Compared to the full sample results, the effects of Japanese news are quite different across the pre-GFC period as the number of significant Japanese news variables (at $95 \%$ or higher) more than doubles, from three to seven. Once again, all significant coefficients are of the expected sign. ${ }^{15}$

Turning to the effects of US and Japanese macro news on the JPY/USD during the GFC period, the third column of Table 3 reports our findings. As the column shows, the number of significant US news remains largely unchanged, at 14 for the GFC sample versus 15 for both the full and the pre-GFC samples. While 13 of the 14 significant US news variables are of the expected sign, one variable, GDP third estimate is not of the expected sign but stems from only one non-zero observation.

The results pertaining to the Japanese news variables over the GFC period are particularly interesting due to the finding that, overall, the influence of Japanese news seems to have largely disappeared. During the GFC period, only two Japanese news variables, machinery orders and TANKAN non-manufacturing, are significant, and only the coefficient estimate of the former is of the expected sign. ${ }^{16}$

It is for the GFC (and subsequent) period(s) not meaningful to compare the average magnitude of the significant news variables by country due to the drop in the

\footnotetext{
${ }^{14}$ The full sample period contains only six non-zero Target Federal Funds rate observations, three of which coincide with the pre-GFC period, thus the associated coefficient estimates are not further discussed.

${ }^{15}$ Not surprisingly, considering that our pre-GFC sample period is almost identical to the 1 January 1999 to 31 October 2006 sample period investigated by Fatum et al. (2012), the individual pre-GFC US and Japanese news variable results reported in the second column are very similar to those described and discussed in their study.

${ }^{16}$ The GFC period encompasses only one non-zero TANKAN manufacturing observation.
} 
number of significant Japanese news variables. However, it is noteworthy that the average estimated influence of the significant US news variables for the GFC period is more than double that of the pre-GFC period (0.0832 versus 0.0360$)$. In other words, even though the number of influential US news is largely unchanged across the pre-GFC and the GFC periods, the average influence of US news is markedly stronger during the latter period. ${ }^{17}$

The fourth column lists the results pertaining to the post-GFC period, 1 February 2009 to 31 August 2016. The results show that during the post-GFC period 13 US news variables are significantly influencing the JPY/USD rate. The average estimated influence of the 13 significant US news variables is similar to that of the GFC period (0.0714 during the post-GFC period compared to, as noted, 0.0832 during the GFC period). All significant US news variables are of the expected sign. As for the intraday influence of Japanese news during the post-GFC period, once again only two types of news, news pertaining to the Japanese trade balance and news pertaining to Japanese construction orders, are associated with significant (at $95 \%$ or higher) coefficient estimates. The trade balance coefficient estimate is of the expected sign, indicating that better than expected Japanese trade balance news are associated with a relative strengthening of the JPY. ${ }^{18}$

Our results so far point to the following insights in regards to the JPY/USD intraday effects of Japanese and US macro surprises. The number of influential US news

\footnotetext{
${ }^{17}$ Furthermore, compared with the pre-GFC period, the GFC period garners a larger adjusted $\mathrm{R}^{2}$ estimate, consistent with improved overall explanatory power of the regressors. However, because the set of regressors include not only the macro news variables but also (three) lags of the exchange rate returns, changes in the adjusted $\mathrm{R}^{2}$ across the different sub-samples does not necessarily reflect changes in the overall explanatory power of the macro news.

${ }^{18}$ The coefficient estimate of the influence of Japanese construction orders is of the unexpected sign but stems from only one non-zero observation.
} 
is markedly higher than the number of influential Japanese news. This is the case for the full sample as well as for the three sub-samples pre-GFC, GFC, and post-GFC. Importantly, while the number of influential US macro news is largely unchanged across the three pre-GFC, GFC, and post-GFC sub-samples, the average influence of the significant US news is markedly higher during and after the GFC, compared to over the pre-GFC period. By contrast, our sub-sample results reveal that from the GFC period and onwards the influence of Japanese macro news has all but disappeared. These results are observed with an increase in the adjusted $\mathrm{R}^{2}$ estimate across the three sample periods.

These are interesting findings for a number of reasons. First, our results suggest that while the influence of US macro news in regards to the number of influential news is largely no different now, after the GFC, than it was before or during the GFC, the average influence of these news is noticeably stronger from the GFC period and onwards. Put differently, our results suggest that the influence of US news on the exchange rate is not subject to noticeable time-dependence in regards to the size or composition of the set of influential US news whereas it is subject to noticeable time-dependence in regards to the overall importance of the influential US news. Second, our results suggest that the influence of Japanese news appears to have weakened dramatically to the point that Japanese news now seem to be almost ignored by foreign exchange market participants.

The documented waning influence of non-US news may well be specific to Japan and rooted in the prolonged period characterized by a largely stalled Japanese economy and accommodating monetary policy stance. Moreover, after two decades of false starts but no real recovery, markets may no longer consider Japanese macro news as important indicators of the state of the Japanese economy and, as a result, markets may thus largely 
ignore news originating from Japan, especially when the global economy is experiencing a sustained period of mooted growth that makes positive changes to the Japanese status quo even more difficult to achieve. However, since our study encompasses only one set of non-US news (and one bilateral USD-rate) it is by construction beyond the scope of our present analysis to consider and compare the evolution of the influence of other nonUS news to the waning influence of Japanese macro news. Rather, the GFC and postGFC near-absence of a discernable influence of Japanese news invites further research to shed light on whether this is a Japan-specific phenomenon or if similar results emerge when considering the intraday exchange rate effects of other non-US macro news during the GFC and post-GFC periods. Similarly, the documented stronger overall importance of the influential US news since the GFC and onwards may be related to the coinciding lack of importance of Japanese news or it may be that markets in general react more strongly to US news during the GFC and post-GFC periods. This also invites further research, specifically in the form of assessing whether the influence of US news is associated with similar strengthening in other bilateral USD-rates.

\subsection{US ZIRP and Japanese QQE}

As discussed earlier, our data sample encompasses a time-period where interest rates in the US are effectively zero, thereby facilitating an investigation of the influence of macro news on intraday exchange rates when economic circumstances in both countries considered are such that regardless of the country origin of news neither country is able to endogenously react to news in the form of traditional monetary policy moves. As a result, financial market expectations of policy reactions to news are likely particularly 
limited during this period of both US and Japanese zero interest rates. Due to the likely absence of expectations of a policy response to news, the overall influence of macro news on exchange rates might be stronger during this particular period.

To investigate if this is indeed the case we consider separately the US ZIRP, 16 December 2008 to 15 December 2015. The results are reported in the fifth column of Table 3. The results show that in regards to the number of significant US and Japanese news, the US ZIRP is similar to the previously discussed GFC and post-GFC sub-periods. Moreover, the average magnitude of the significant coefficient estimates for US news during the US ZIRP is 0.0694 . At roughly twice the size of the average estimated influence of significant US news during the pre-GFC period, the US ZIRP average is almost identical to that of the post-GFC period and, in fact, slightly less than that of the GFC period. Our US ZIRP results, therefore, do not indicate that news during this particular period exert a stronger or for that matter noticeably different influence on the JPY/USD rate compared to either the GFC period or the post-GFC period. ${ }^{19}$

We also consider separately the intraday exchange rate effects of macro news during the recent (and on-going) Japanese period of QQE. We do so since the Japanese QQE period of additional monetary easing may have modified financial market expectations to consider an increased possibility of non-traditional policy responses to news. As a result, the overall influence of macro news on exchange rates might be less pronounced during this particular period. We consider this possibility by investigating separately the subset of the post-GFC period that constitutes the Japanese QQE period, 5 April 2013 to 31 August 2016, and report the results in the sixth column of Table 3. Our

\footnotetext{
${ }^{19}$ Due to the very considerable overlap of the post-GFC period and the US-ZIRP it is unsurprising that our findings across these two periods are very similar.
} 
results lend some credence to the suggestion that, overall, the influence of macro news during the Japanese QQE period has weakened, at least with respect to US news. For the Japanese QQE period we find only 9 significant US news with an average estimated influence of 0.0516 , i.e. the set of influential US news is smaller compared to the other sub-samples considered and the average of the significant coefficient estimates is less than that of any other sub-sample with the exception of the pre-GFC period. The nearabsence of influential Japanese news remains unchanged. ${ }^{20}$

\subsection{Good versus Bad News}

The results of estimating Equation (2) and our investigation of good versus bad news asymmetries are reported in Tables 4A through 4C. Table 4A (Table 4B) pertains to the estimations across only good (bad) news while Table 4C displays the coefficient estimates associated with the difference between good and bad news. Tables 4A and 4B show that the previously discussed main results in regards to the relative importance of US and Japanese news are generally robust to the separation of good from bad news. Pertinent to the issue of possible asymmetries, Table 4C indicates that significant asymmetric effects of good compared to bad news are mostly absent in our data. We find only three instances of asymmetric effects for the full sample period, five for the preGFC period, seven for the GFC period, one and two for the post-GFC period and US ZIRP, respectively, and none for the Japanese QQE period.

If we consider in more detail the sample with the highest number of significant asymmetric effects, the GFC period (column three), we find two US instances where

\footnotetext{
${ }^{20}$ We interpret the Japanese QQE specific results with some caution due to the possibility of an unaccounted for structural break stemming from the 29 January 2016 introduction of negative Japanese interest rates.
} 
good news matter more than bad news (business inventories and Target Federal Funds rate), one US instance where bad news matter more than good news (GDP second estimate), one Japanese instance where good news matter more than bad news (TANKAN large manufacturing), two Japanese instances where bad news matter more than good news (GDP preliminary and machinery orders), and one Japanese instance where negative news matter more than good news but the negative news is of the unexpected sign (capacity utilization). Clearly, the seven GFC-specific asymmetries do not point to a systematic pattern and thus do not support any conclusions in regards to whether either good or bad news are more influential. Similarly, we find no systematic pattern of asymmetries for any of the other samples considered. Furthermore, comparing the average estimated influence of significant good news to that of significant bad news, pairwise across each sample, does not generate further insights. Therefore, while our investigation of asymmetries confirms the robustness of our main findings we do not find evidence of systematically different effects of good versus bad news. ${ }^{21}$

\section{Extensions and Robustness}

In this section we extend and check the robustness of our main results by considering lagged effects of news, by employing alternative model specifications in lieu of the baseline estimations, and by assessing the influence of news separately across US and Japanese macro news.

First, we re-estimate Equation (1) with $\mathrm{K}=1$ and, subsequently, $\mathrm{K}=2$, i.e. we expand the baseline model to include the first and, subsequently, the first and the second

\footnotetext{
${ }^{21}$ In light of the mostly sparse empirical evidence in support of bad versus good news asymmetries presented by Andersen et al. (2003), Fatum et al. (2012), and others, it is not surprising that we are unable to discern systematically different effects of good versus bad news.
} 
lag of US and Japanese macro news. In doing so we assess whether macro news are associated with delayed intraday exchange rate effects while we at the same time check the robustness of our previously discussed contemporaneous intraday exchange rate effects of macro news based on $\mathrm{K}=0$. Tables $5 \mathrm{~A}$ and $5 \mathrm{~B}$ report the contemporaneous and the first lag coefficient estimates from the $\mathrm{K}=1$ estimations, respectively. As the first of the tables shows, the inclusion of the first lag of news does not alter the estimated contemporaneous effects, i.e. whether $\mathrm{K}=0$, as in the baseline models, or $\mathrm{K}=1$, the findings with respect to contemporaneous effects of news are unchanged. Turning to Table 5B, the results suggest the presence of only few significant delayed (first lag) effects. A closer inspection of the significant estimates suggests that several of the delayed effects are consistent with a market adjustment of the contemporaneous effect to the extent that the contemporaneous and first lag effects are of opposite signs and, furthermore, the magnitude of the latter is smaller (in absolute terms) than the magnitude of the former. When we re-estimate Equation (1) with $\mathrm{K}=2$ we once again find the contemporaneous effects to be robust to the change in the news lag structure, we find the aforementioned first-lag effects of news to be similarly unaffected, and we find a few significant second lag effects. ${ }^{22}$ Overall, the extension of the baseline model to allow for lagged effects of news confirm both the robustness of our results with respect to contemporaneous effects of news and, consistent with the findings of Andersen et al. (2003) and others, that the effects of news are typically immediate and short-lived.

Second, we check the robustness of our main results by re-estimating Equation (1) using the previously discussed 100-minute windows approach and by estimating the event study regressions described in Equation (3). Table 6 shows the results pertaining to

\footnotetext{
${ }^{22}$ Results pertaining to the $\mathrm{K}=2$ estimations are not shown for brevity.
} 
the estimations based on 100-minute windows and Table 7 shows the results of the event study regressions. As Table 6 shows, discarding the data points outside the 100-minute windows surrounding the news announcements does not influence our results except for a few very minor changes in regards to some of the coefficient estimate magnitudes. In fact, the results reported in Table 6 support the exact same conclusions as those of our baseline estimations. Turning to Table 7 , the event study results show more variation in the sense that in addition to changes in coefficient magnitudes the number of influential US and Japanese news for some of the sub-samples change slightly. Nevertheless, the results are qualitatively unchanged and the previously discussed conclusions remain unaffected by the adoption of event study regressions.

Third and final, we re-assess the influence of news by estimating Equation (1) separately across Japanese and US news. The results, reported in Table 8, are very similar to the baseline results (reported in Table 3) and, therefore, further support the previously discussed conclusions. For completeness, we also re-estimate Equation (1) separately across Japanese and US news, using the 100-minute windows procedure and, once again, the results are unchanged. ${ }^{23}$

\section{Conclusion}

In this paper we investigate the intraday influence of US and Japanese macro news on the JPY/USD exchange rate over the pre-GFC period, during the GFC period, and over the post-GFC period. To do so we consider the influence of 40 different types of macro news surprises (23 different types of US macro surprises and 17 different types of Japanese

\footnotetext{
${ }^{23}$ Results pertaining to the estimation of Equation (1) separately across US and Japanese news using the 100-minute windows procedure are not shown for brevity.
} 
macro surprises) on 5-minute indicative JPY/USD rate quotes separately over the preGFC (1 January 1999 to 31 July 2007), the GFC (1 August 2007 to 31 January 2009), and the post-GFC (1 February 2009 to 31 August 2016) periods.

Our results suggest that more than half of the number of US news considered is influential across the full sample as well as across each of the pre-GFC, the GFC, and the post-GFC periods, and that this number is markedly higher than the corresponding numbers of influential Japanese news. Interestingly, we find that even though the number and the composition of the set of influential US news are largely unchanged across the pre-GFC, the GFC, and the post-GFC periods, the average influence of US news is markedly increased during the two more recent periods to the point that the average influence of the significant US news during the post-GFC period has doubled relative to the pre-GFC period. Our results, therefore, are consistent with the suggestion that the effect of US macro news on the exchange rate is subject to noticeable time-dependence with respect to the relative importance of the influential US macro news and, specifically, that the overall importance of these US news has increased.

Our results pertaining to the Japanese news are very different from those of the US news. Most noticeably, we find that from the GFC period and onwards the influence of Japanese macro news has all but disappeared. This waning influence of Japanese news is a particularly interesting finding that invites further research to shed light on whether this is a Japan-specific phenomenon or if similar results emerge when considering the intraday exchange rate effects of other non-US macro news before, during, and after the GFC. 


\section{References}

Andersen, T.G., Bollerslev, T., Diebold, F.X.,Vega, C., 2003. Micro effects of macro announcements: real-time price discovery in foreign exchange. American Economic Review 93, 38-62.

Andersen, T.G., Bollerslev, T., Diebold, F.X.,Vega, C., 2007. Real-time price discovery in global stock, bond and foreign exchange markets. Journal of International Economics 73, 251-277.

Arai, N., 2016. The effects of monetary policy announcements at the zero lower bound. International Journal of Central Banking, forthcoming.

Chaboud, A.P., Chernenko, S.V., Howorka, E., Iyer, R.S.K., Liu, D., Wright, J.H., 2004. The high-frequency effects of U.S. macroeconomic data releases on prices and trading activity in the global interdealer foreign exchange market. Board of Governors of the Federal Reserve System, International Finance Discussion Papers No. 823.

Chatrath, A., Miao, H., Ramchander, S., 2014. Currency jumps, cojumps and the role of macro news. Journal of International Money and Finance 40, 42-62.

Clarida, R., Waldman, D., 2007. Is bad news about inflation good news for the exchange rate?, NBER Working Paper No. 13010.

Dacorogna, M.M., Müller, U.A., Nagler, R.J., Olsen, R.B., Pictet, O.V., 1993. A geographical model for the daily and weekly seasonal volatility in the foreign exchange market. Journal of International Money and Finance 12, 413-438.

Danielsson, J., Payne, R., 2002. Real trading patterns and prices in spot foreign exchange markets. Journal of International Money and Finance 21, 203-222.

Evans, K., Speight, A., 2010. International macroeconomic announcements and intraday euro exchange rate volatility. Journal of the Japanese and International Economies 24, $552-568$.

Evans, M.D.D., Lyons, R.K., 2008. How is macro news transmitted to exchange rates?. Journal of Financial Economics 88, 26-50.

Fatum, R., Hutchison, M.M., Wu, T. 2012. Asymmetries and state dependence: the impact of macro surprises on intraday exchange rates. Journal of the Japanese and International Economies 26, 542-560.

Fatum, R., Scholnick, B., 2008. Monetary policy news and exchange rate responses: do only surprises matter?. Journal of Banking and Finance 32, 1076-1086. 
Faust, J., Rogers, J.H., Wang, S.-Y., Wright, J.H., 2005. The high-frequency response of exchange rates and interest rates to macroeconomic announcements. Journal of Monetary Economics 54, 1051-1068.

Hashimoto, Y., Ito, T., 2010. Effects of Japanese macroeconomic statistic announcements on the dollar/yen exchange rate: high-resolution picture. Journal of the Japanese and International Economies 24, 334-354.

Li, W., Wong, M.C.S., Cenev, J., 2015. High frequency analysis of macro news releases on the foreign exchange market: a survey of the literature. Big Data Research 2, 33-48.

Melvin, M., Taylor, M.P., 2009. The crisis in the foreign exchange market. Journal of International Money and Finance 28, 1317-1330.

Newey, W.K., West, K.D., 1987. A simple, positive, semi-definite, heteroscedasticity and autocorrelation consistent covariance matrix. Econometrica 55, 703-708. 
Table 1. Summary statistics for five-minute JPY/USD returns

\begin{tabular}{ccccccc}
\hline \hline & Mean & Maximum & Minimum & Std. dev. & Skewness & Kurtosis \\
\hline \hline FULL & -0.000005 & 1.111 & -3.074 & 0.031 & -1.312 & 122.575 \\
Pre-GFC & 0.000005 & 0.700 & -1.394 & 0.032 & -0.213 & 34.310 \\
GFC & -0.000174 & 0.686 & -1.827 & 0.047 & -0.884 & 48.345 \\
Post-GFC & 0.000018 & 1.111 & -3.074 & 0.027 & -3.585 & 374.804 \\
US-ZIRP & 0.000040 & 1.111 & -1.835 & 0.028 & -1.338 & 122.868 \\
JP-QQE & 0.000018 & 0.636 & -3.074 & 0.018 & -17.202 & 2586.581 \\
\hline \hline
\end{tabular}


Table 2. US and Japanese Macro Surprises

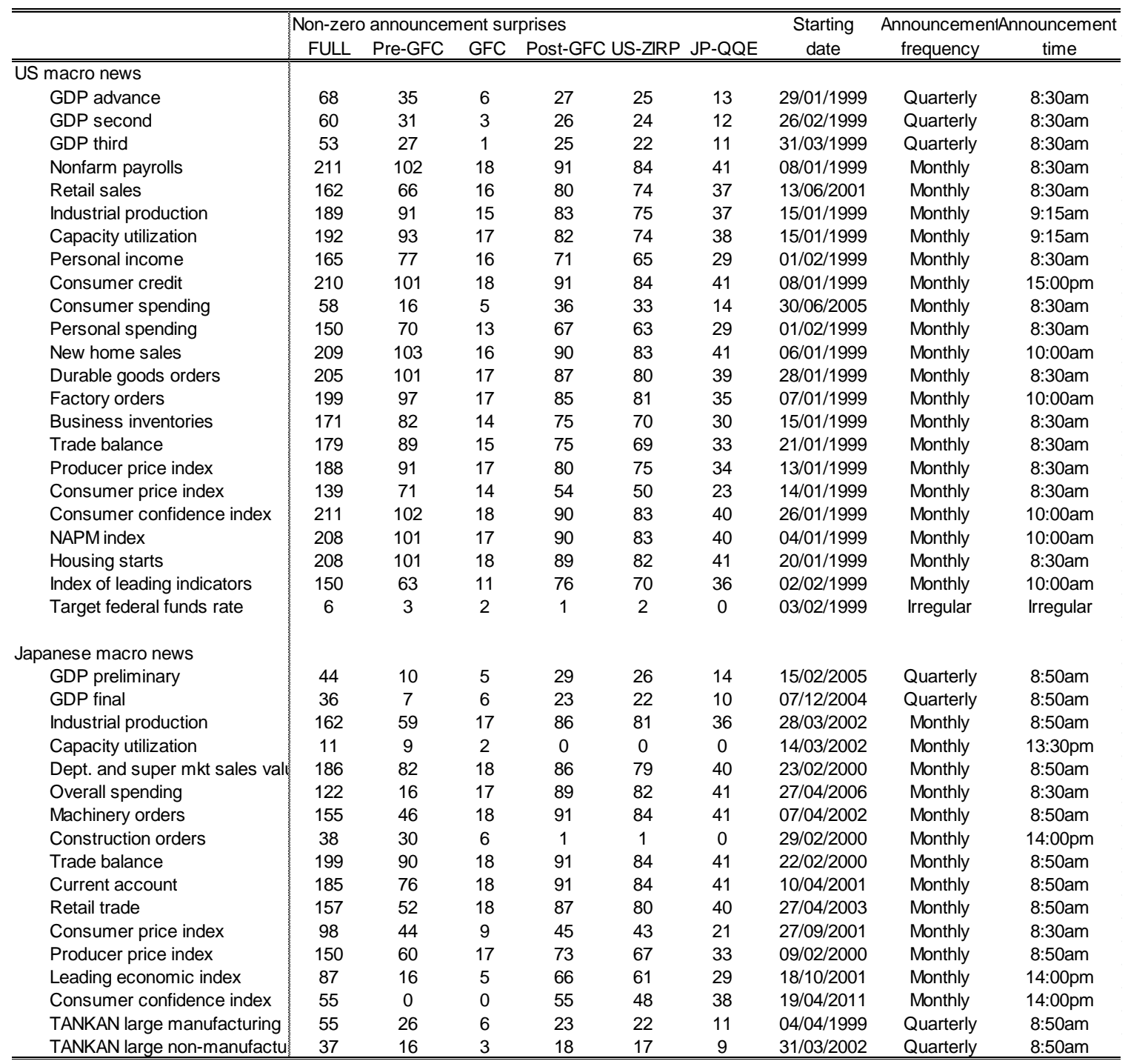




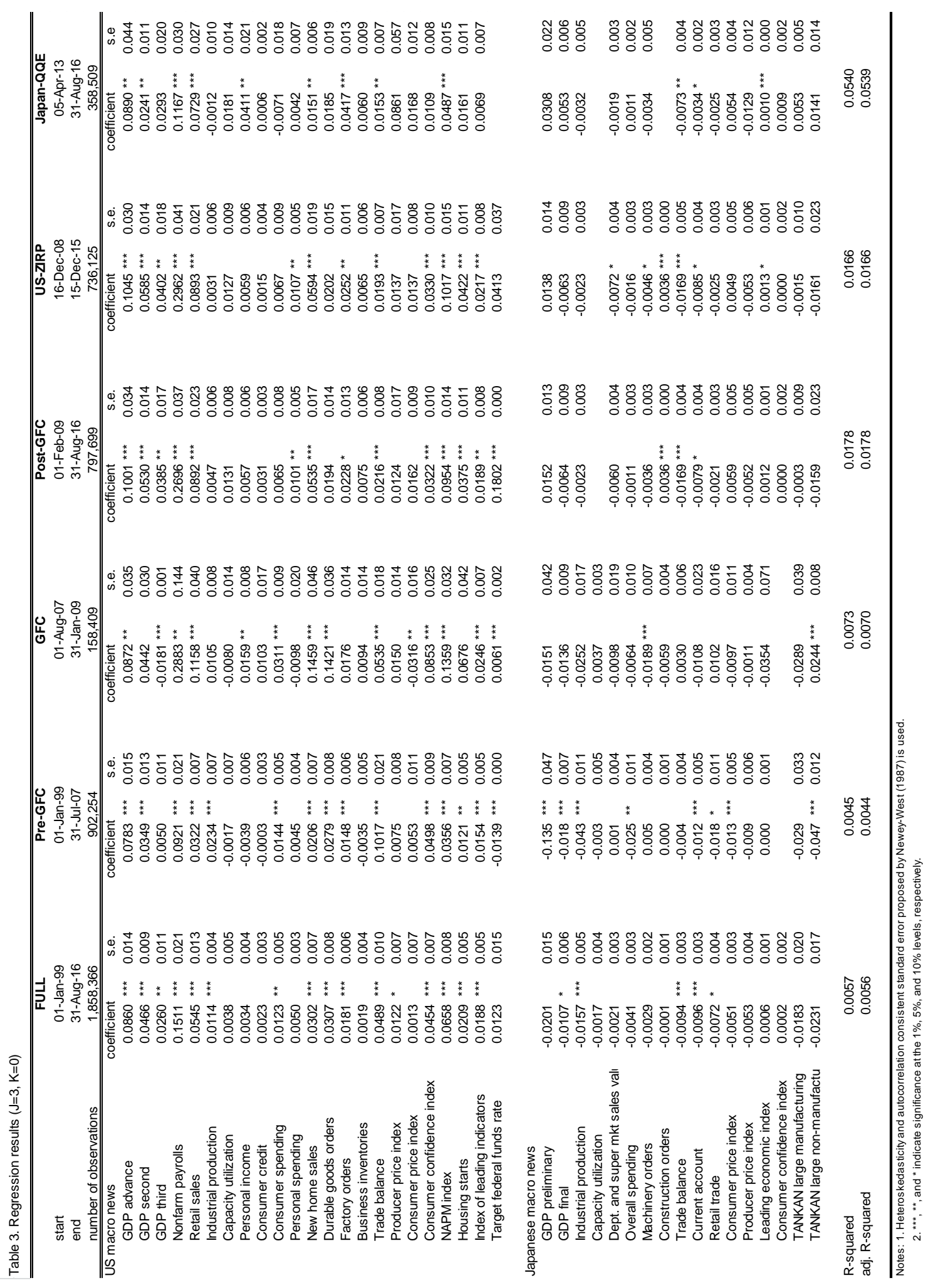




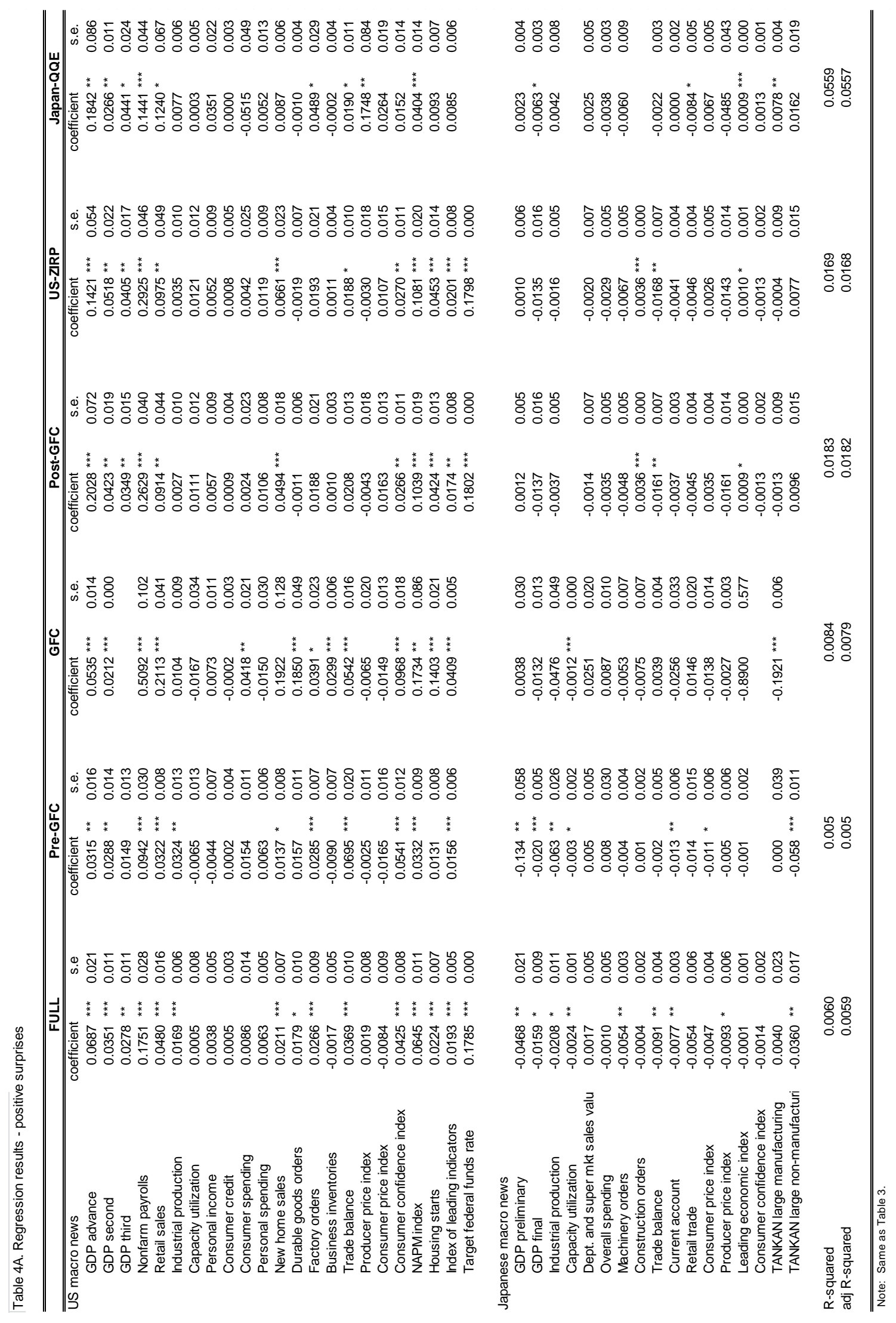




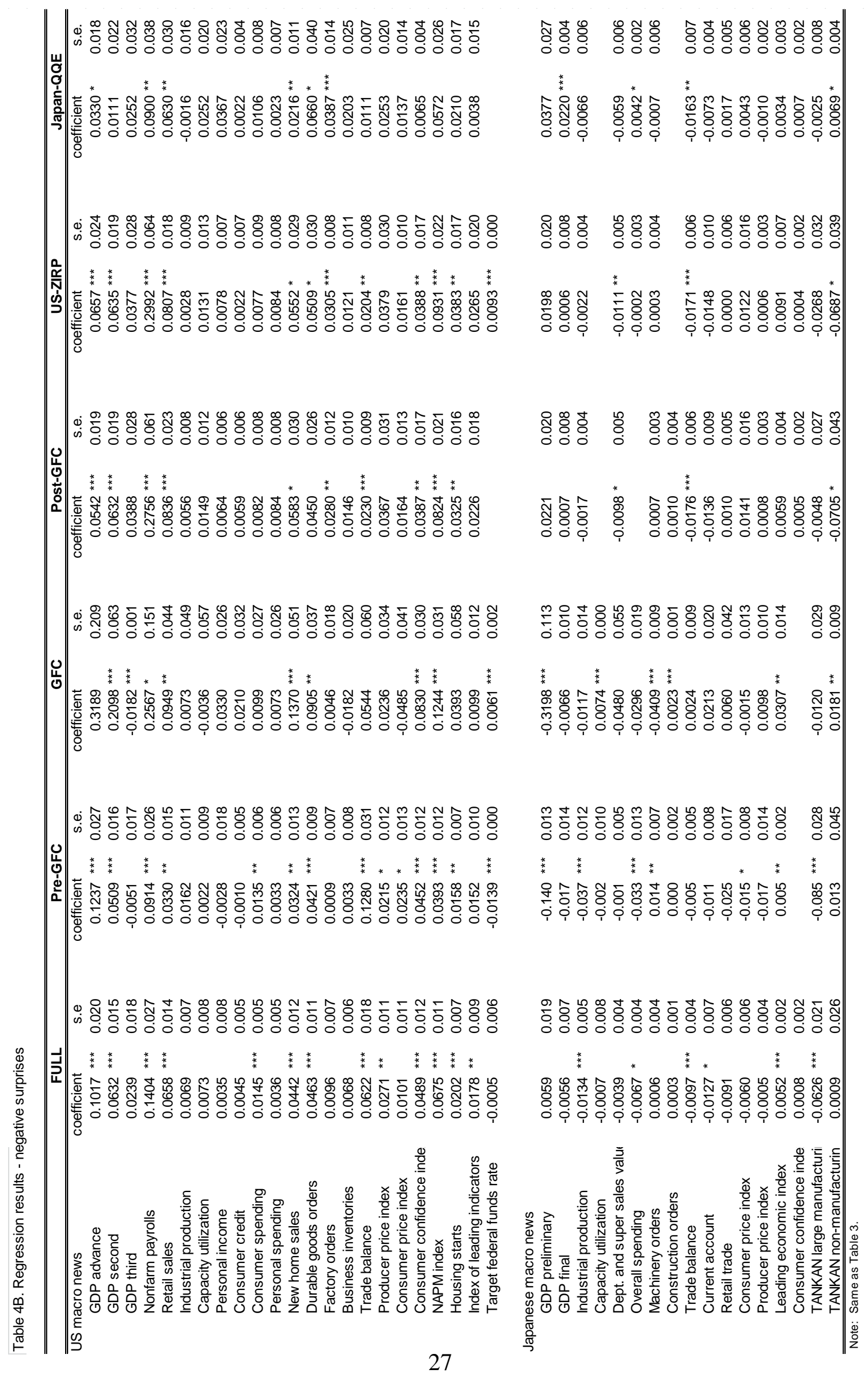




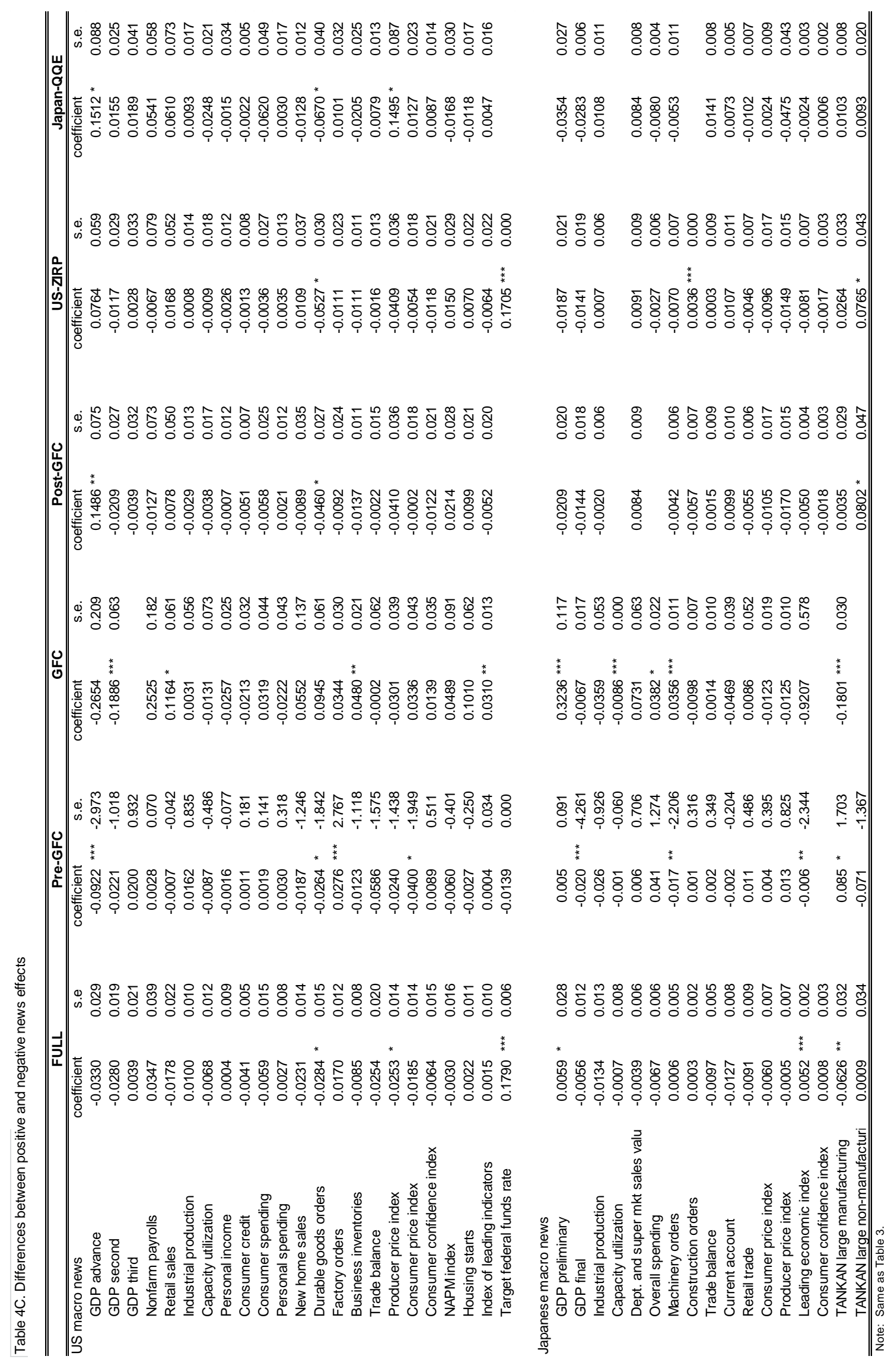




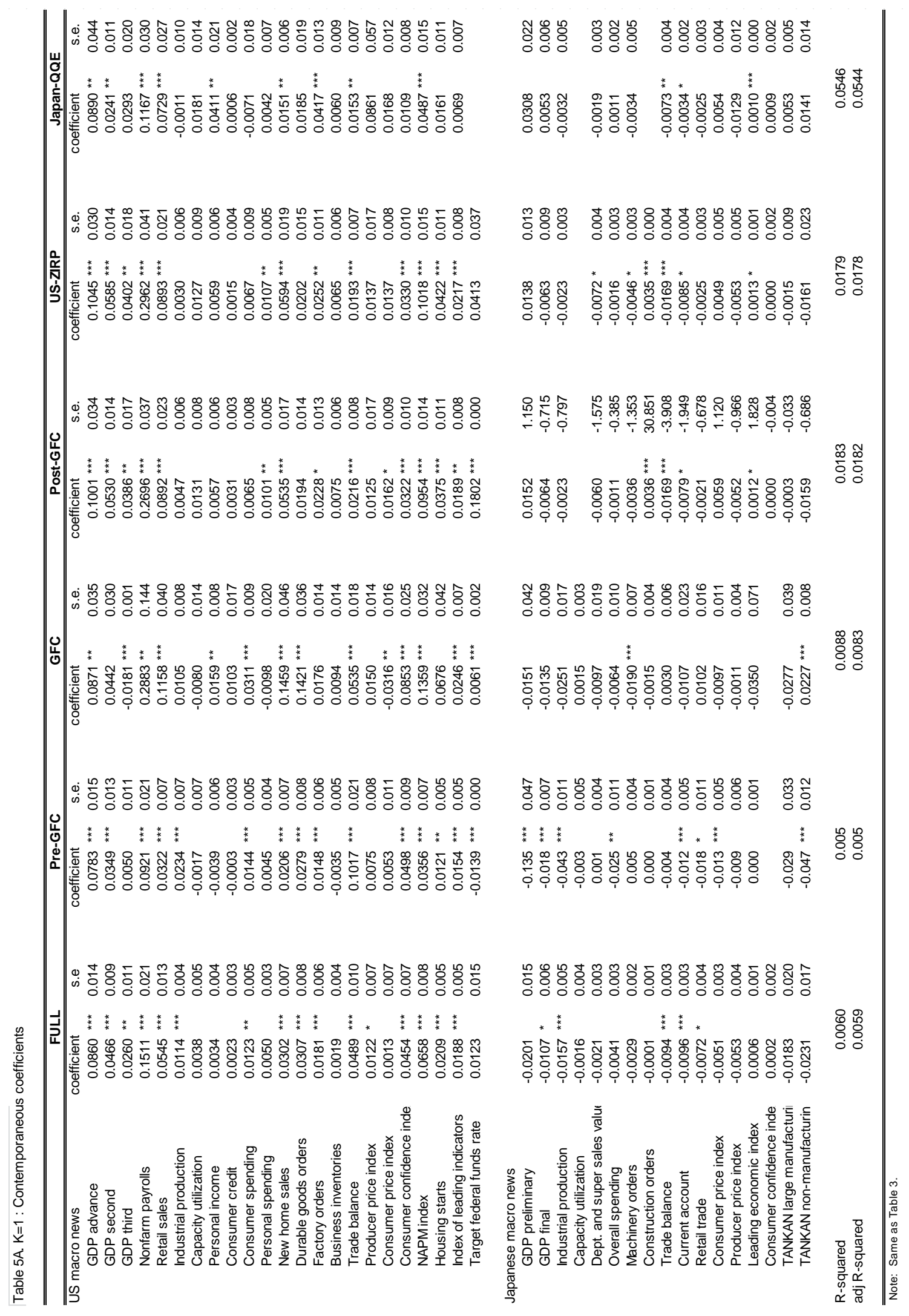




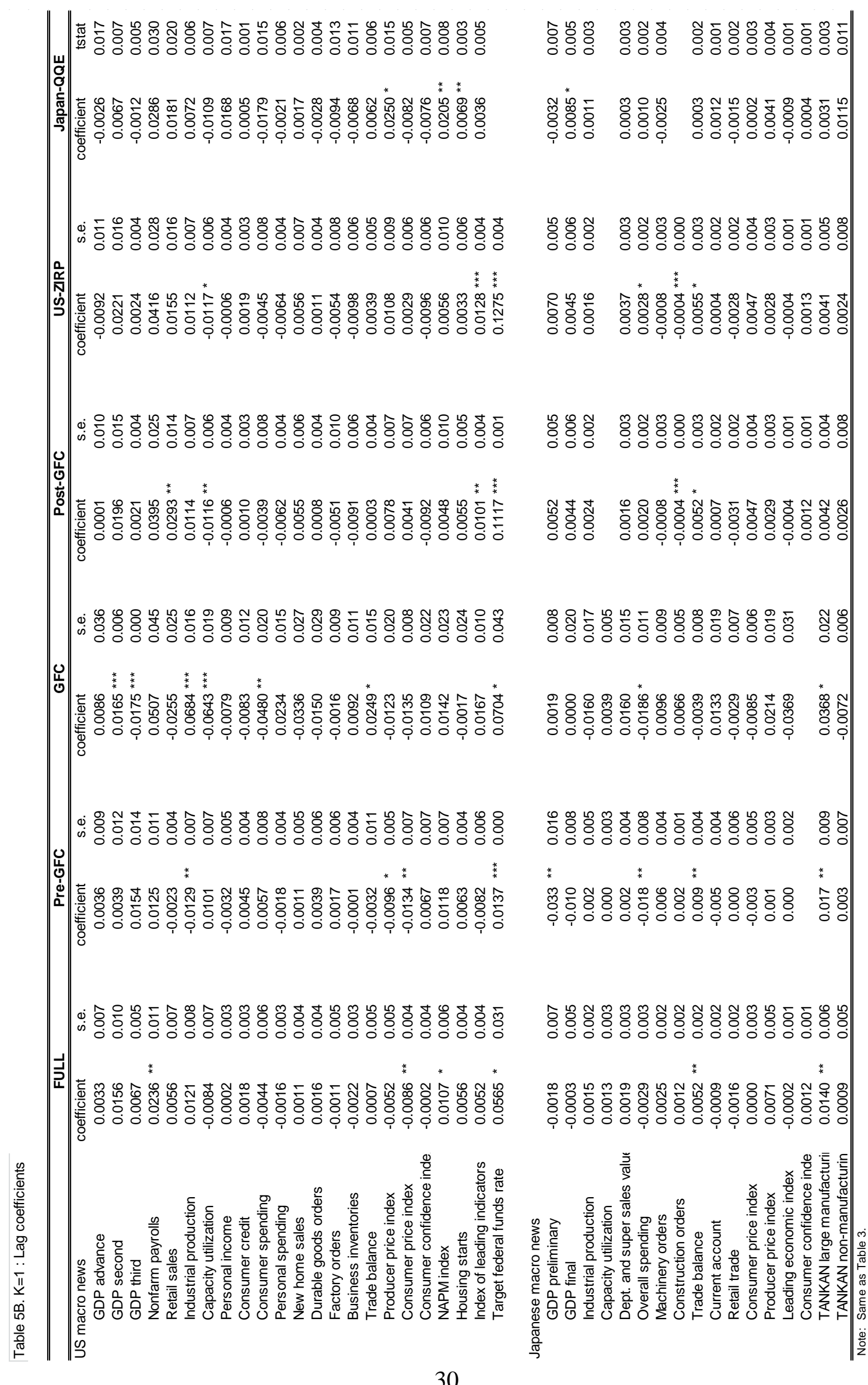




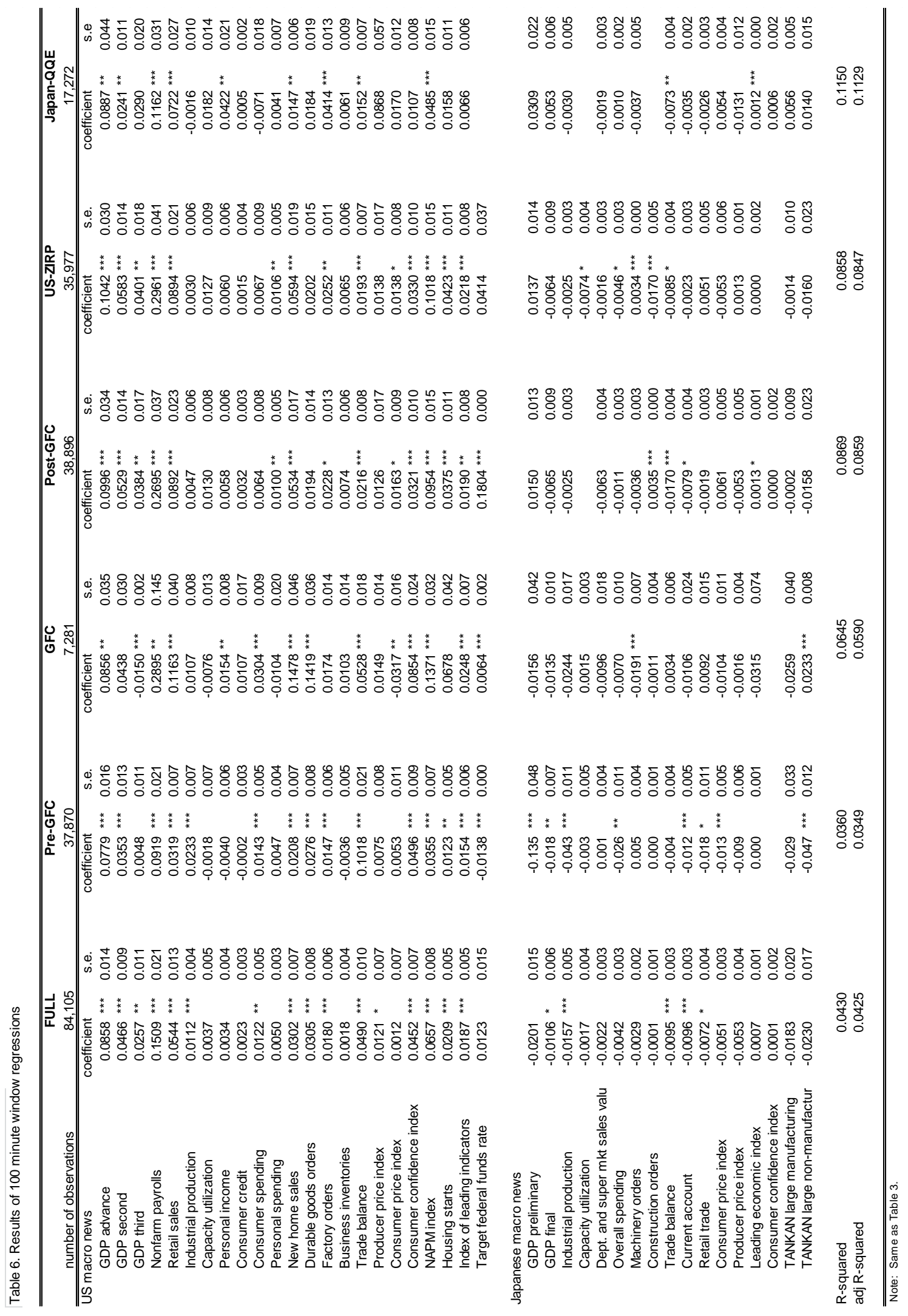




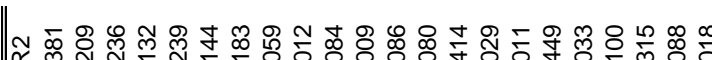
w

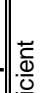

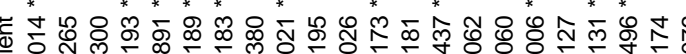

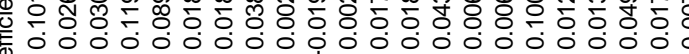
○

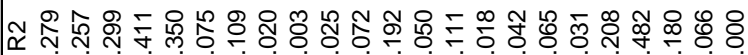

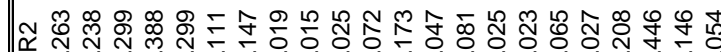
8

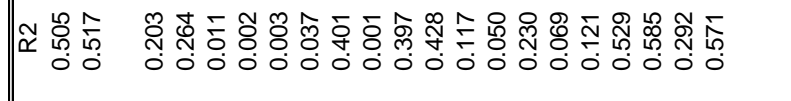

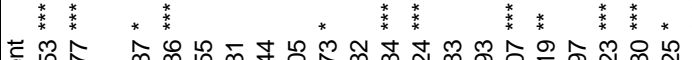

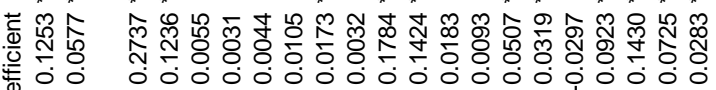

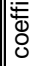

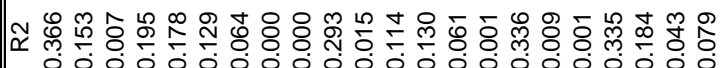

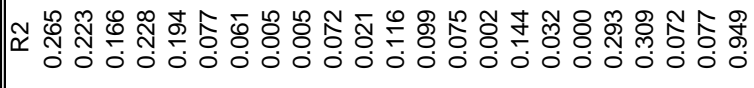

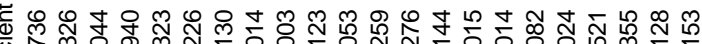

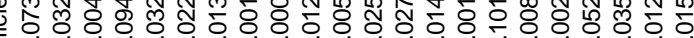

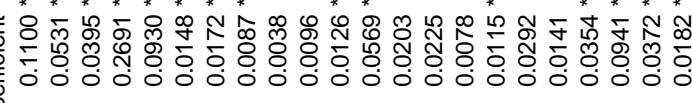

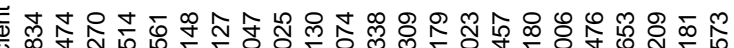

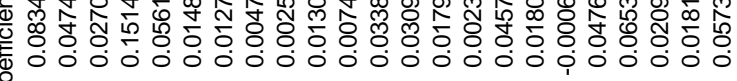
○

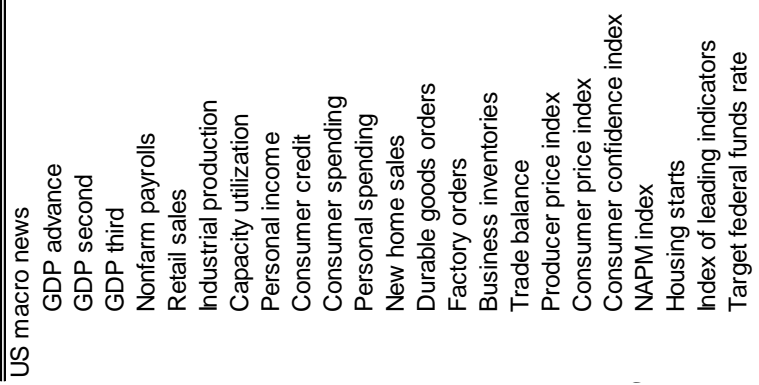

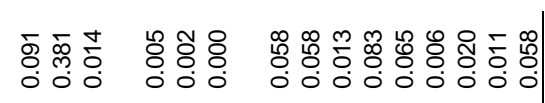

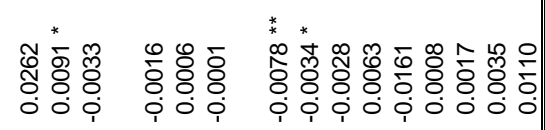

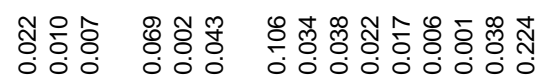

กิ

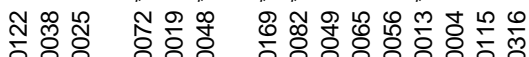

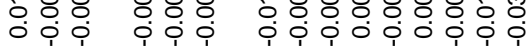

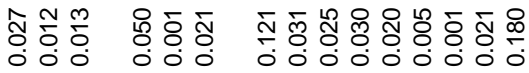

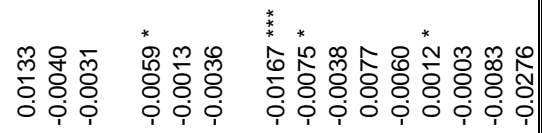

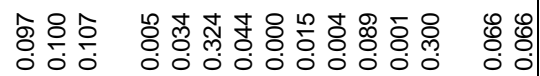

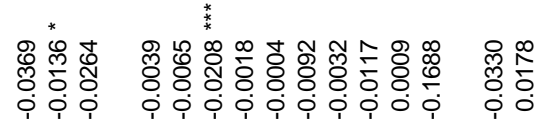

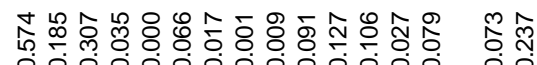

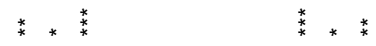

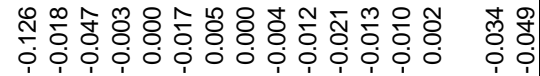

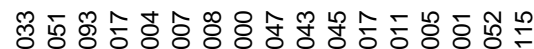

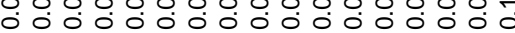

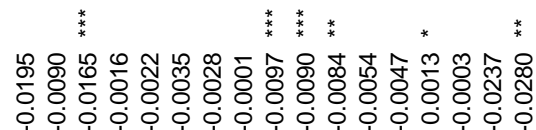

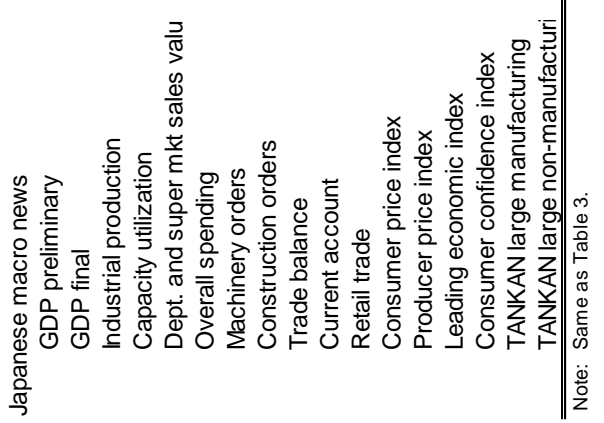




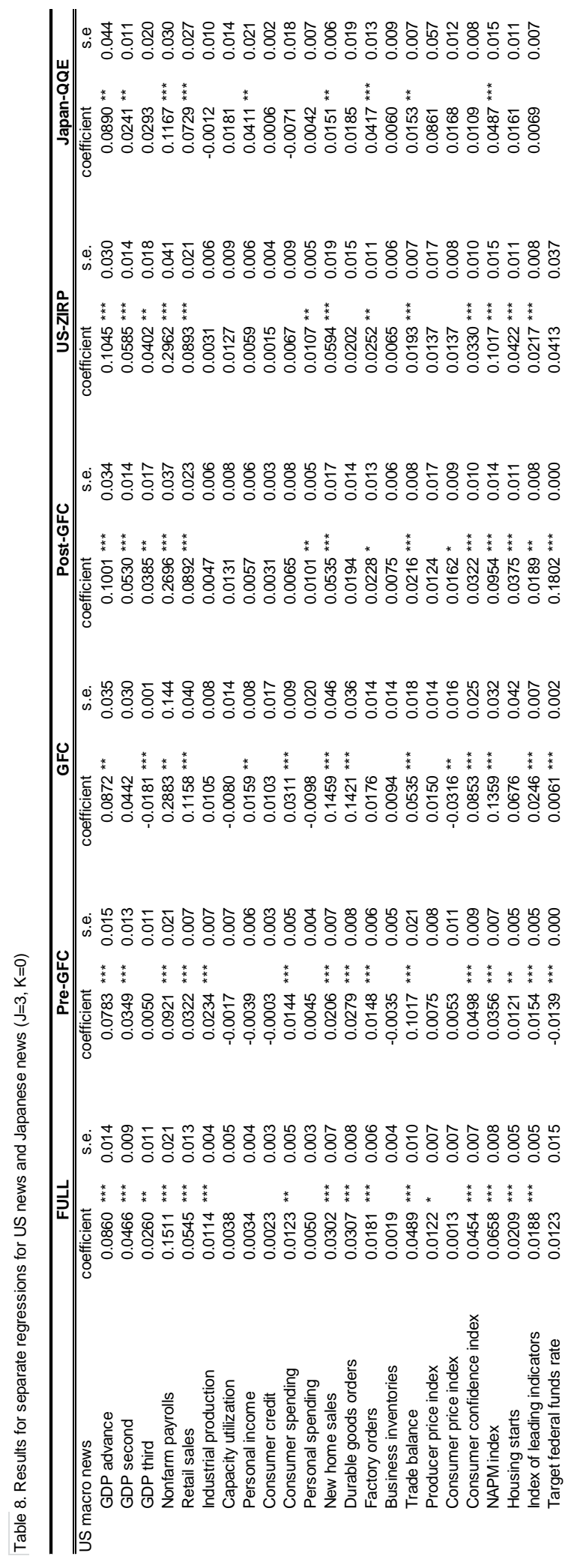

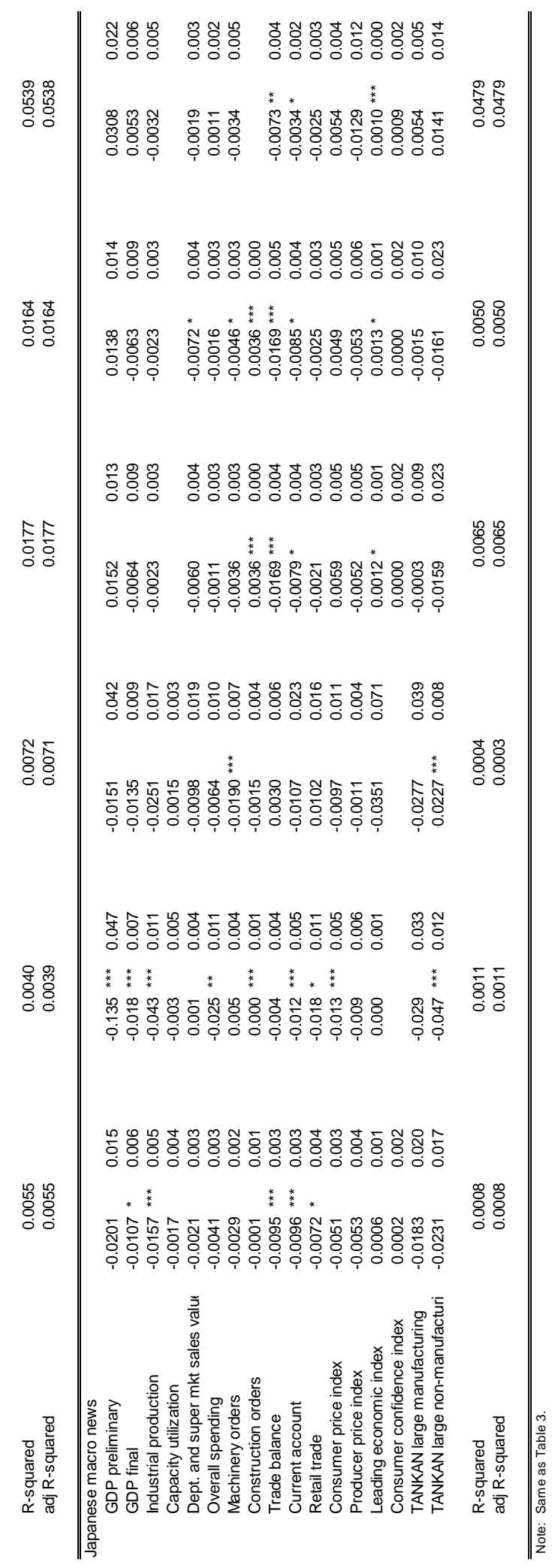

